\title{
Potential of post-impact hydrothermal minerals as paleo-atmospheric proxies: The case of Rochechouart (France)
}

\author{
GUILLAUME AVICE ${ }^{1}$, ANTONIN RICHARD ${ }^{2}$ AND \\ LUDOVIC FERRIÈRE ${ }^{3}$
}

${ }^{1} \mathrm{CNRS}$ IPGP/UMR 7154

${ }^{2}$ Université de Lorraine - CNRS - CREGU - GeoRessources

${ }^{3}$ Natural History Museum

Presenting Author: avice@ipgp.fr

Planetary atmospheres are important reservoirs controlling many parameters defining a planet's habitability (e.g. [1]). Temporal changes of the elemental and isotopic composition of volatile elements in the Earth's atmosphere reflect the entire geological history of our planet [2]. However, paleo-atmospheric proxies are scarce and prevent from drawing a clear picture of Earth's evolution through geological time.

In this study, we explored the potential of post-impact hydrothermal minerals as new paleo-atmospheric proxies. We measured the elemental and isotopic composition of $\mathrm{Ne}, \mathrm{Ar}, \mathrm{Kr}$, and $\mathrm{Xe}$ in fluids released from fluid inclusions contained in quartz and carbonate crystals from hydrothermal veins and breccia fillings from the $206.92 \pm 0.32$ Myr old Rochechouart impact structure in France [3]. Petrographic observations reveal the presence of primary fluid inclusions within quartz and carbonate samples (Fig. 1). Fluid inclusion assemblages indicate coeval trapping of liquid + vapor, liquid-only, and vapor \pm liquid inclusions. This is possibly indicative of the boiling of an aqueous fluid at low-pressure conditions under a high geothermal gradient. Noble gas analyses confirm a strong atmospheric signature for the fluids. For neon, only two samples show deviations relative to air, one with a contribution from nucleogenic $\mathrm{Ne}$ and one showing mass-dependent isotopic fractionation of $\mathrm{Ne}$ isotopes, maybe due to diffusive loss from this sample. ${ }^{38} \mathrm{Ar} /{ }^{36} \mathrm{Ar}$ ratios are air-like and ${ }^{40} \mathrm{Ar} /{ }^{36} \mathrm{Ar}$ ratios cluster around 300 . The isotopic compositions of $\mathrm{Kr}$ and $\mathrm{Xe}$ are identical, within errors, to the composition of the modern Earth's atmosphere (Fig. 2).

Results obtained in this study demonstrate the promising potential of post-impact hydrothermal minerals as paleoatmospheric proxies.

[1]Dehant et al. (2019) Space Science Reviews 215, 42. [2] Catling \& Zahnle (2020) Sci. Adv. 6, eaax1420. [3] Cohen et al. (2017) Meteorit. Planet. Sci. 52, 1600-1611;

Figure 1 Petrographic observations. A: Quartz vein cutting through hydrothermally altered host rocks. Alternative clear and dark sectors indicate variable abundances of fluid inclusions. B: Fluid inclusion assemblage indicative of coeval trapping of liquid + vapor, liquid-only, and vapor \pm liquid inclusions.

Figure 2 Average isotopic composition of krypton (a) and xenon (b) of gas released from five samples from Rochechouart (error at 1s).
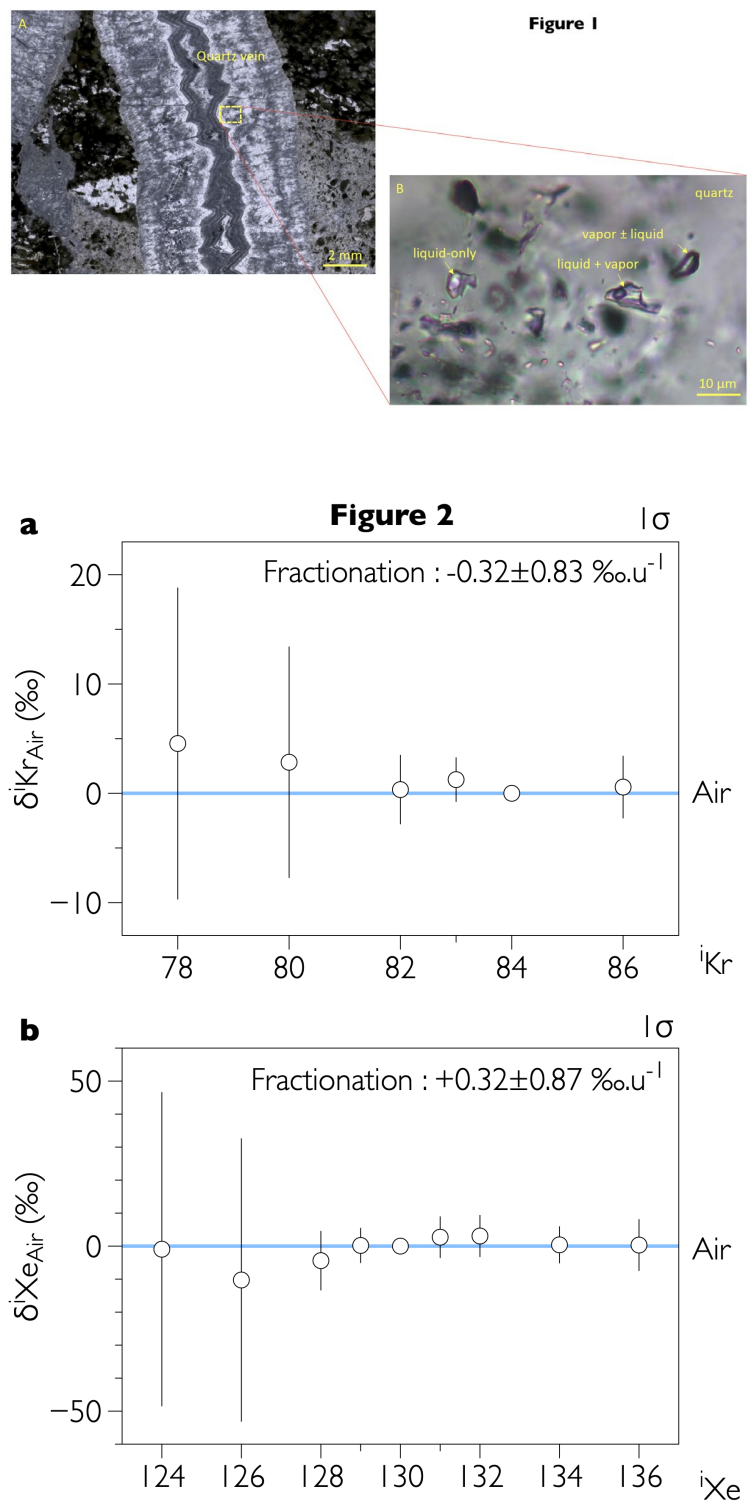